Gut, 1964, 5, 517

\title{
Ileo-caecal granulomata
}

\author{
F. D. LEE AND A. D. ROY \\ From the Departments of Pathology and Surgery, Western Infirmary, Glasgow
}

EDITORIAL SYNOPSIS The present confusion concerning the classification and terminology of granulomatous lesions of the ileo-caecal area is pointed out. Fifteen cases are reviewed with regard to clinical presentation, operative findings, and post-operative development. The tissues removed from these patients are critically reviewed with regard to features which would classify them as tuberculosis, Crohn's disease, or ulcerative colitis. In two cases demonstration of acid-fast bacilli suggests the diagnosis of ileo-caecal tuberculosis; one case was due to appendicular inflammation but in the other cases the histological picture suggests Crohn's disease, and clinically their behaviour is that of Crohn's disease. It is concluded, therefore, that unless acid-fast bacilli are demonstrated, these granulomata should be regarded as examples of Crohn's disease and terms such as 'right-sided colitis', 'ileo-colitis', and 'cicatrizing entero-colitis' should be discarded. Resection of these lesions is advocated with conservation of as much bowel as possible.

Chronic granulomatous lesions of the intestine are especially interesting when they occur in the ileocaecal region. The histology of such lesions may present the features of three diseases, namely, ulcerative colitis, Crohn's disease, or tuberculosis, and they may even co-exist in one specimen. Some of these cases are said to be examples of a specific disease, enterocolitis, with a course and prognosis of its own. Aetiology presents several problems, being apparently clear in cases where acid-fast bacilli are demonstrated and obscure when they are not. But even the diagnosis of tuberculosis may rest on insecure foundations unless the tubercle bacillus is cultured. It is in the light of these problems that 15 patients who were admitted to the Western Infirmary from 1952 to June 1963 have been reviewed. It will be seen that the frequency of these lesions in this area is low. Total surgical admissions were 70,000 of which 1,064 cases were classified as of chronic colitis or ileitis. The 15 cases are reviewed in two ways. First, a clinical review of their presentation, operative procedures and progress, and then the histology of tissues removed at operation is discussed.

\section{CLINICAL REVIEW}

Table I and Fig. 1 summarize the details.

There were 11 females and four males, and their ages ranged from 22 to 69 with a mean of 37 years. Although there was a disproportionate number of Jewish patients in a series of cases of right-sided colitis described by Hughes (1963) and in a group of
TABLE I

ORIGINAL AND REVISED DIAGNOSIS COMPARED

\begin{tabular}{|c|c|c|c|c|}
\hline \multirow[b]{2}{*}{ Case } & \multicolumn{2}{|l|}{ Operation } & \multicolumn{2}{|l|}{ Diagnosis } \\
\hline & First & Second & Original & Reviewed \\
\hline 1 & Appendicectomy & & Crohn's & $\begin{array}{l}\text { Chronic } \\
\text { appendicitis }\end{array}$ \\
\hline $\begin{array}{l}2 \\
3\end{array}$ & $\begin{array}{l}\text { Hemi-colectomy } \\
\text { Biopsy }\end{array}$ & $\begin{array}{l}\text { Hemi- } \\
\text { colectomy }\end{array}$ & $\begin{array}{l}\text { Crohn's } \\
\text { a Crohn's } \\
\text { or tuberculosis } \\
\text { b Crohn's }\end{array}$ & $\begin{array}{l}\text { Crohn's } \\
\text { Crohn's }\end{array}$ \\
\hline 4 & Resection ileum & $\begin{array}{l}\text { Ileo-trans. } \\
\text { anast. }\end{array}$ & $\begin{array}{l}\text { a Crohn's } \\
\text { b Crohn's or } \\
\text { tuberculosis }\end{array}$ & Crohn's \\
\hline $\begin{array}{l}5 \\
6 \\
7 \\
8\end{array}$ & $\begin{array}{l}\text { Hemi-colectomy } \\
\text { Hemi-colectomy } \\
\text { Hemi-colectomy } \\
\text { Hemi-colectomy }\end{array}$ & $\begin{array}{l}\text { Resection } \\
\text { colon and } \\
\text { ileum }\end{array}$ & $\begin{array}{l}\text { Tuberculosis } \\
\text { Crohn's } \\
\text { Entero-colitis } \\
\text { a Tuberculosis } \\
\text { b Crohn's }\end{array}$ & $\begin{array}{l}\text { Tuberculosis } \\
\text { Crohn's } \\
\text { Crohn's } \\
\text { Crohn's }\end{array}$ \\
\hline $\begin{array}{r}9 \\
10 \\
11\end{array}$ & $\begin{array}{l}\text { Hemi-colectomy } \\
\text { Hemi-colectomy } \\
\text { Appendicectomy }\end{array}$ & $\begin{array}{l}\text { Hemi- } \\
\text { colectomy }\end{array}$ & $\begin{array}{l}\text { Crohn's } \\
\text { Tuberculosis } \\
\text { a Crohn's } \\
\text { b Crohn's }\end{array}$ & $\begin{array}{l}\text { Crohn's } \\
\text { Tuberculosis } \\
\text { Crohn's }\end{array}$ \\
\hline 12 & Hemi-colectomy & $\begin{array}{l}\text { Ileal resec- } \\
\text { tion }\end{array}$ & $\begin{array}{l}\text { a Ulcerative } \\
\text { colitis } \\
\text { b Crohn's }\end{array}$ & Crohn's \\
\hline $\begin{array}{l}13 \\
14\end{array}$ & $\begin{array}{l}\text { Ileo-trans. anast. } \\
\text { Appendicectomy }\end{array}$ & $\begin{array}{l}\text { Hemi- } \\
\text { colectomy }\end{array}$ & $\begin{array}{l}\text { Tuberculosis } \\
\text { a Appendicitis } \\
\text { b Crohn's }\end{array}$ & $\begin{array}{l}\text { Tuberculosis } \\
\text { Crohn's }\end{array}$ \\
\hline 15 & Hemi-colectomy & & Crohn's & Crohn's \\
\hline
\end{tabular}

'cases of regional colitis' (Neuman, Bargen, and Judd, 1954), none of our patients was Jewish.

By far the commonest symptom was abdominal colic which occurred in all patients and early in the course of the disease. Ten patients also had diarrhoea of varying severity but only six had episodes of vomiting. In four patients there was some rectal bleeding. In none had steatorrhoea been demon- 


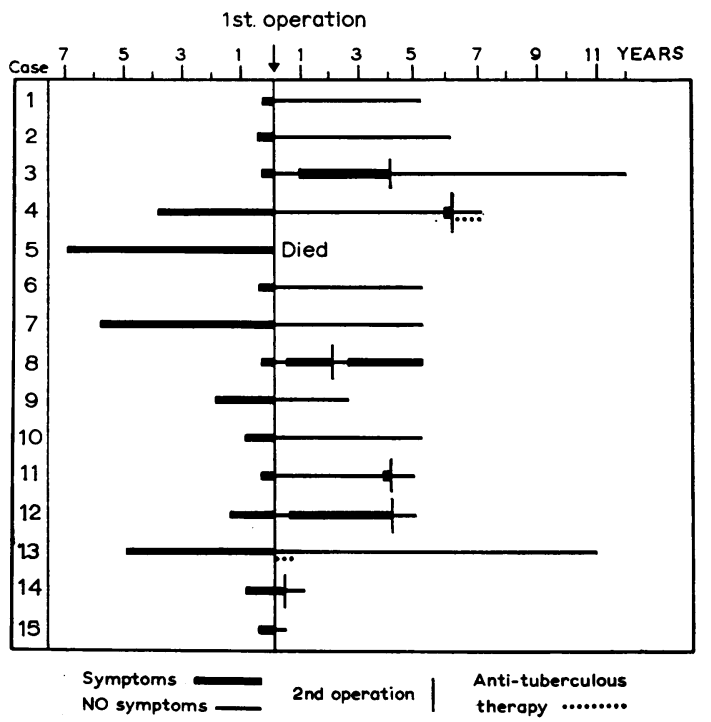

FIG. 1. Diagram of the clinical course of 15 patients.

strated. Unfortunately liver function tests had not been carried out in any of these cases. Ten patients had a clearly defined mass in the right lower abdomen which was tender at some time in all the cases. None was acutely obstructed. In 11 patients barium enema examinations were performed, and in five the lesion was diagnosed as a carcinoma, in four as inflammatory, and in one as hypertrophic ileo-caecal tuberculosis. In only one was no lesion demonstrated. Six patients had small bowel studies and five of these showed evidence of an inflammatory lesion in the terminal ileum which was described as being probably Crohn's disease. Six patients had chest radiographs, none showing evidence of active or healed tuberculosis. One (case 3), however, had a radiograph of the hand showing what might have been a sarcoid lesion of the ring finger and his Mantoux test was negative, but in the seven years since the radiograph no other sarcoid lesions have appeared and he remains well.

All patients had been operated upon at least once. In every case an inflammatory mass was present in the caecum, and in all except one case it was involving the terminal ileum as well. In three patients an obvious abscess was present and in these the appendix was removed. One patient had no further trouble (case 1), the second (case 11) required a right hemicolectomy four years later, and the third (case 14) a right hemicolectomy two months later. Thirteen patients had a resection of a variable amount of ileum, caecum, and ascending colon. In case 4 only the ileum was resected though the caecum was involved; as a result, four years later an anastomosis was required to relieve a recurrence of the symptoms. In case 3 the first operation was only a laparotomy with biopsy of a peritoneal nodule, but a resection was required four years later. In cases 8 and 12 a second resection was performed two years and four years after the first resection respectively. Only one patient (case 13) had a short circuit as the only procedure.

In four patients the histological diagnosis differed between the two operations. In case 4 it was changed from Crohn's disease to tuberculosis but without acid-fast bacilli being demonstrated. In case 8 it was changed from tuberculosis to Crohn's disease, again with no acid-fast bacilli demonstrated. In case 12 it was changed from ulcerative colitis to Crohn's disease. In case 14 it was changed from subacute appendicitis to Crohn's disease. There was only one post-operative death (case 5), a woman of 69 who died of peritonitis. Of the remaining 14, seven patients have been well for at least five years and another one for two years, after the last operation. Two patients (cases 4 and 11) have only been followed for a short time after the last operation, being lost to follow-up thereafter. One patient (case 12) has very recently had a further resection. Two patients (cases 14 and 15) have only recently been operated on. One patient (case 8) is known to have continued symptoms three years after the operation, consisting of steatorrhoea with macrocytic anaemia, and small bowel studies strongly suggest recurrent lesions in the terminal ileum. Two patients (cases 4 and 13) have had anti-tuberculous drugs. None have had symptoms since, but one has only been followed for a year. Case 10 was diagnosed as tuberculosis but had no anti-tuberculosis therapy and is well seven years after operation.

On clinical grounds these 15 cases are so similar in their behaviour that it might be suggested that a single disease process is present.

\section{PATHOLOGICAL REVIEW}

It is apparent that from the clinical standpoint all the cases in our series have tended to behave in a similar way, and generally speaking the pathological changes also fall into a similar pattern. Macroscopically, all cases showed thickening and stenosis of the caecum and terminal ileum, with or without involvement of the appendix and ascending colon, and no case presented any outstanding feature. The distribution of the lesions is shown in Figure 2.

Histologically, all cases show some or all of the following changes:-Submucosal thickening due either to connective tissue proliferation or oedema; focal or diffuse round-cell infiltration mainly located in the submucosa; giant-cell systems in any part of 
1.

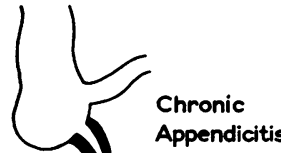

8.

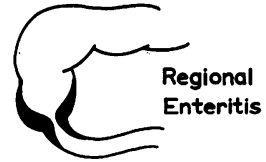

9.

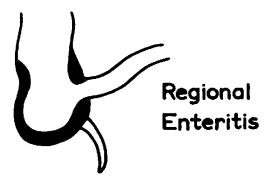

3.

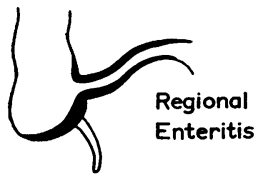

4.

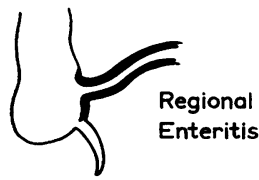

5.

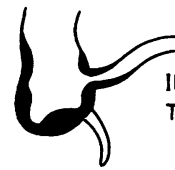

Tuberculosis 13

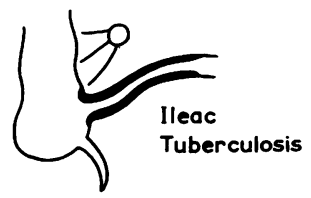

6.
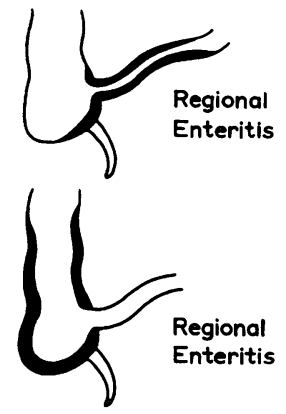
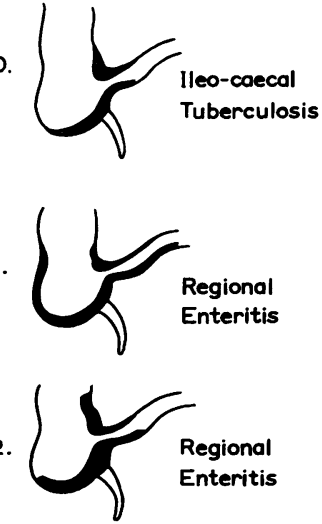

11.

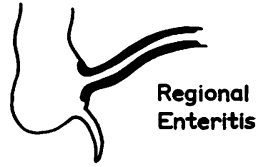

15.

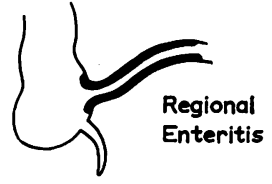

FIG. 2. The distribution of the lesions.

the bowel wall and in the regional lymph nodes; evidence of mucosal damage either in the form of ulceration, crypt abscesses, or metaplastic change; fistula formation with the development of abscesses in the bowel wall.

The diagnosis initially made in the 15 cases is recorded in Table I, and appeared to depend on the main site of the lesion, the predominant histological change, and the demonstration or otherwise of the tubercle bacillus in the lesions. The diagnosis was changed in five cases, and misinterpretation of the

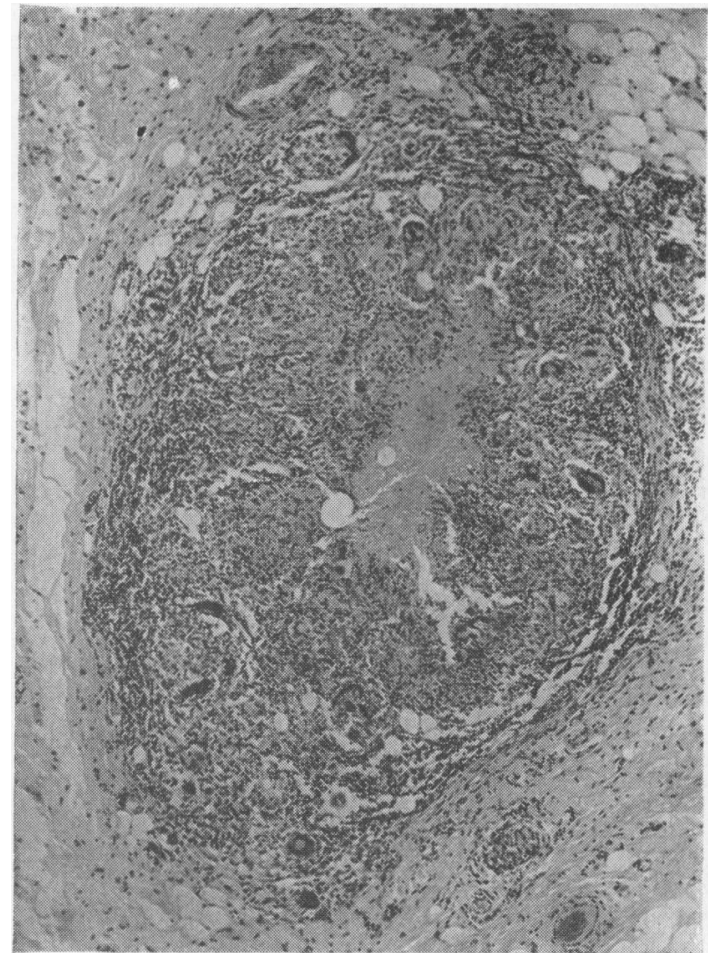

FlG. 3. Case 5: early caseation within a giant-cell system in the submucosa of the ileo-caecal region in tuberculosis. Haemalum and eosin $\times 50$.

nature of the lesions appears to have arisen from undue emphasis being placed on certain histological findings, particularly in relation to the site of the lesions.

Two cases (5 and 10) are immediately separated from the group by the demonstration of acid- and alcohol-fast bacilli in the lesions. In these cases, ileo-caecal tuberculosis would have been suspected in any case, since caseation within the giant-cell systems is a prominent feature in some sections (Fig. 3); in other sections, however, caseation is minimal or absent, and acid-fast bacilli can only be found after prolonged search and the appearances are indistinguishable from those of Crohn's disease. This serves to stress the importance of attempting to culture the tubercle bacillus from bowel lesions, which should be standard procedure in lesions of this kind. Two other cases (8 and 13) were also diagnosed initially as ileo-caecal tuberculosis. The only pathological material available in case 13 was an omental nodule, which histologically showed a caseating giant-cell system close to a lymph node. Since no acid-fast bacilli were demonstrated (in this lesion) the diagnosis, although likely, can neither be confirmed nor rejected. In case 8 , the initial 


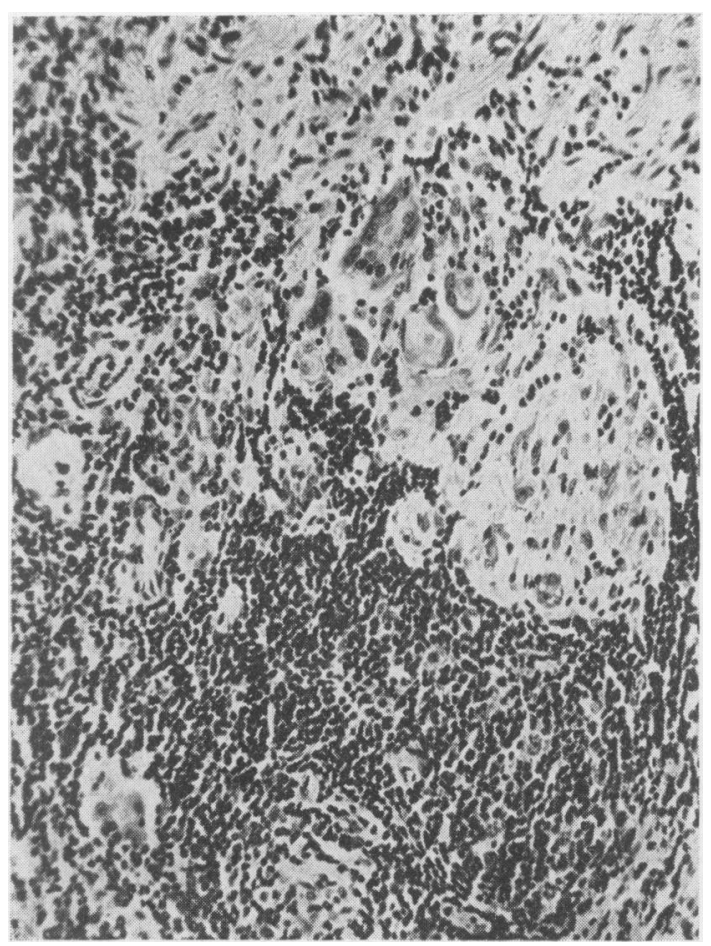

FIG. 4.

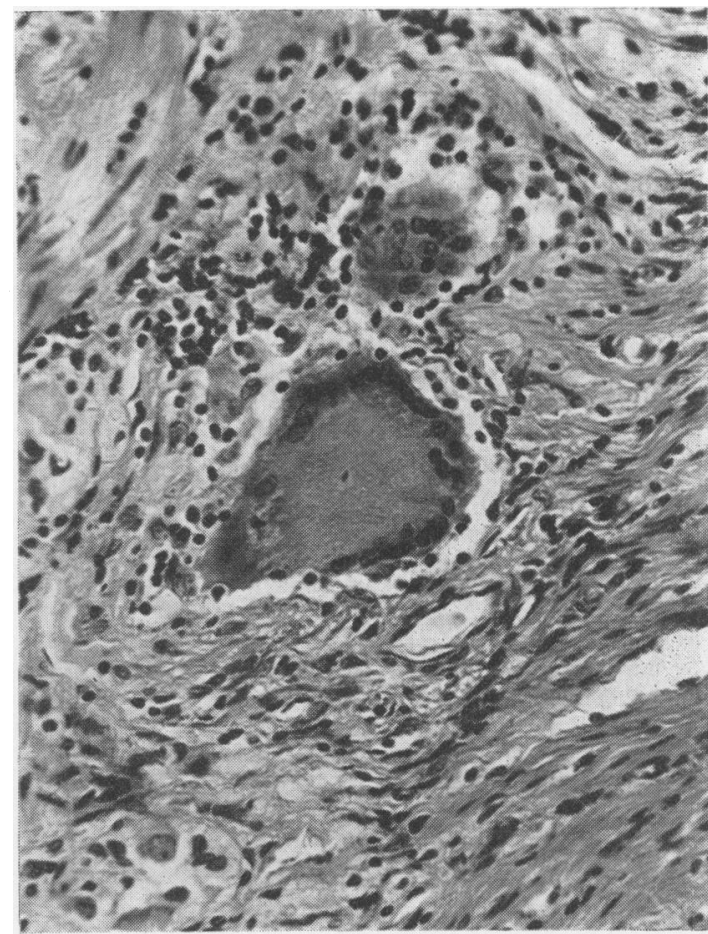

FIG. 5 .

FIG. 4. Case 15: focal lymphocytic infiltration with a developing but non-caseating giant-cell system at the seroso. muscular junction in the terminal ileum in regional enteritis. Haemalum and eosin $\times 80$.

FIG. 5. Case 15: giant cells of Langhan's type within lymph channels in regional enteritis. This is also seen in tuberculosis. Haemalum and eosin $\times 150$.

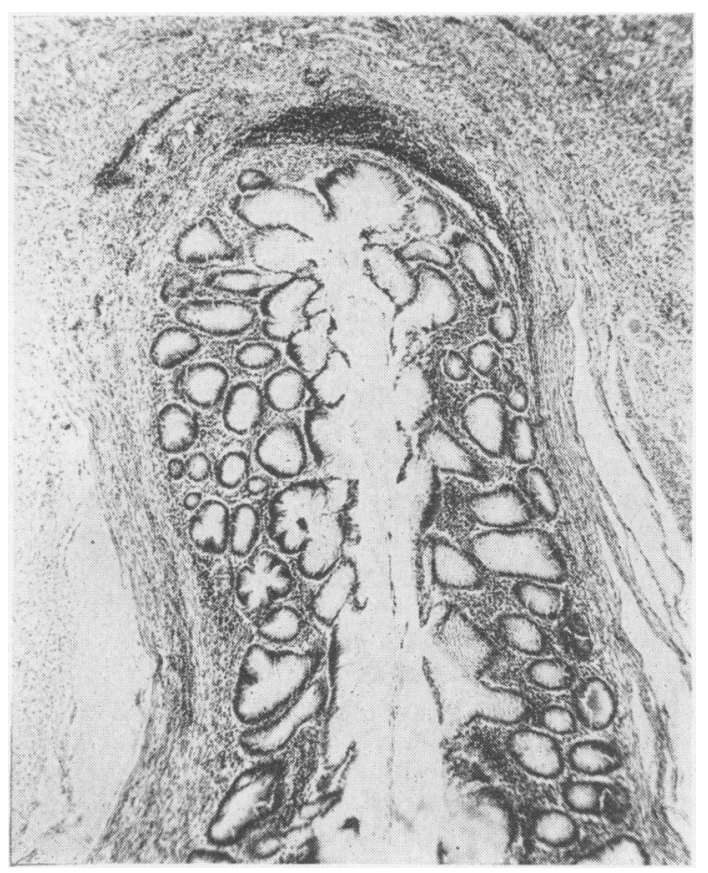

FIG. 6.

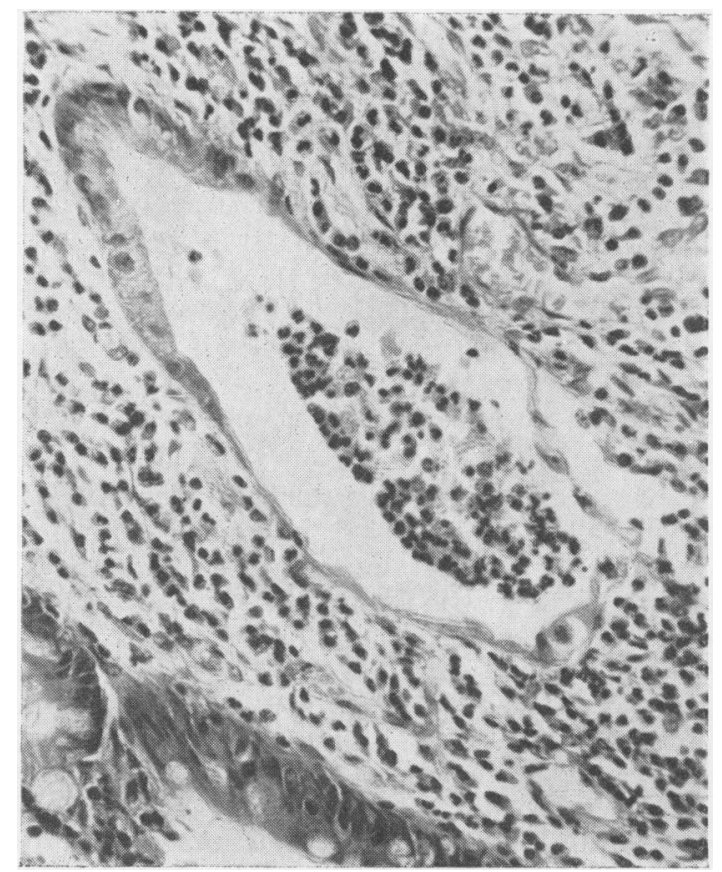

FIG. 7.

FIG. 6. Case 1: appendicular diverticulum with associated non-specific inflammatory infiltration. Haemalum and $e \operatorname{cosin} \times 25$.

FIG. 7. Case 12: crypt abscess in the caecum in a probable case of regional enteritis. Haemalum and eosin $\times 150$. 
diagnosis of tuberculosis is seriously questioned, since the tubercle bacillus was not demonstrated; the bowel lesion recurred and presented the characteristic features of Crohn's disease, including the absence of acid-fast bacilli histologically and negative cultures for tuberculosis. This case is thus considered to be one of Crohn's disease from the outset.

A diagnosis of Crohn's disease was initially made in eight cases $(1,2,3,4,6,9,11$, and 15). In these cases the diagnosis was based upon the localized nature of the disease process and the predominance in histological sections of such changes as submucosal oedema, focal lymphoid infiltration, and non-caseating giant-cell systems in the bowel wall (Figs. 4 and 5) coupled, of course, with absence of acid-fast bacilli in the lesions. Culture for tuberculosis was only carried out in four cases $(6,9,11$, and $15)$ and the diagnosis is thus subject to reservation in the remainder. Only in case 1 , however, is the diagnosis seriously challenged. In this patient only the appendix was removed at operation and Crohn's disease was considered to be the most likely diagnosis due to the presence of small giant-cell systems in the serosal coat. Appendicectomy is unlikely to arrest the progress of Crohn's disease, and recurrence is likely requiring further resection of the ileum and caecum (cf. case 14). No such complication was encountered in case 1 , and further examination of the histological sections revealed the presence of an inflamed diverticulum which would account for the marked periappendicular inflammation (Fig. 6). A diagnosis of simple chronic appendicitis appears to be more likely than Crohn's disease restricted to the appendix.

In one case (12) ulcerative colitis was initially diagnosed on the basis of the histological findings in the caecum, in which the formation of crypt abscesses is prominent (Fig. 7). It is significant, however, that the pathological changes were confined to the caecum and terminal ileum, in the latter situation closely resembling Crohn's disease both macroscopically and histologically. Further, there was fistula formation with a pericaecal abscess and the distal colon was not diseased. The initial diagnosis is doubted since the disease recurred in the terminal ileum and further resection revealed the pathological changes characteristic of Crohn's disease. It is probable, therefore, that this is a case of Crohn's disease with predominant involvement of the caecum in the first instance rather than a subvariety of ulcerative colitis or 'right-sided colitis' (Butler, 1956; Hughes, 1963).

Case 7 is similar to the previous case, but the pathological diagnosis is much less readily defined. The lesions were found mainly in the caecum and ascending colon, although the terminal ileum was

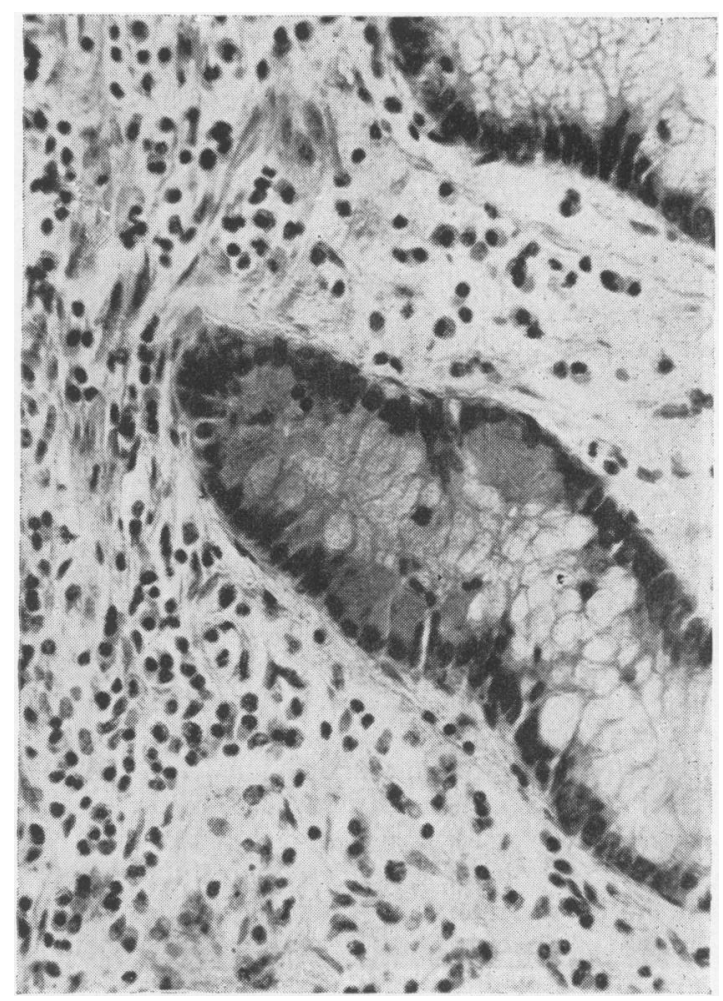

FIG. 8. Case 7: Paneth cells in the colonic mucosa. Haemalum and eosin $\times 165$.

also diseased. Histologically, the presence in the colonic mucosa of crypt abscesses and Paneth cells (Fig. 8) might indicate ulcerative colitis (Watson and Roy, 1960), whereas the submucosal thickening with connective tissue proliferation and lymphoid infiltration, with non-caseating giant-cell systems in the submucosa and in the regional lymph nodes is more suggestive of Crohn's disease. This diagnostic dilemma was initially resolved by employing the term 'cicatrizing entero-colitis' (Lumb, 1951), presumably to indicate that the disease process represented a form intermediate between typical Crohn's disease in the ileum and classical ulcerative colitis in the rectosigmoid region. On pathological grounds alone, however, we believe that this case is more readily classified as of Crohn's disease; this diagnosis would also be substantiated by the clinical history, since there was no tendency towards the development of symptoms associated with ulcerative colitis. It is conceded nonetheless that there is room for doubt in cases of this nature.

Finally, in case 14, only the appendix was removed at the first operation and was diagnosed histologically as subacute appendicitis, with a strong suspicion 
of Crohn's disease. Symptoms recurred necessitating right hemi-colectomy two months later, and the excised ileum and caecum presented the typical features of Crohn's disease, including negative culture for tuberculosis.

\section{DISCUSSION}

The diagnosis in each case after reviewing the histological findings is recorded in Table I. It would appear that granulomatous disease of the ileocaecal region is predominantly a manifestation of Crohn's disease with tuberculosis as the only significant alternative. The clinical features and follow-up studies reflect the essential similarity of the pathological findings. The importance of excluding tuberculosis is thus pre-eminent in cases of this nature. Ulcerative colitis in the classical sense could not be implicated in any of our cases, although some of the histological characteristics of this disease may be found when Crohn's disease involves the proximal colon (Yarnis, Marshak, and Crohn, 1957). Only in case 7 is there serious doubt; the clinical picture, however, does not differ greatly from the unequivocal cases of Crohn's disease in our series, and the employment of a different diagnostic label appears unjustified. It is always possible, of course, that a granulomatous lesion of the caecum may be a complication of appendicitis, as in case 1 .

Nomenclature has bedevilled the classification of granulomatous disease of the caecal region. Ileocaecal tuberculosis must stand as a diagnosis when the acid-fast bacillus is demonstrated and caseation is present, but even then its close clinical and histological resemblance to Crohn's disease make one wonder if there cannot be some connexion between these two diseases. The diagnosis, however, should certainly no: be made when the tubercle bacillus had neither been seen histologically nor cultured.

Right-sided colitis, cicatrizing entero-colitis, ileocolitis, and chronic caecal granuloma are all terms which are used to describe similar lesions in the ileocaecal region, and when such terms are employed then differences in aetiology are likely to be inferred. We feel, like Lockhart-Mummery and Morson (1960), that apart from the diseases caused by specific microorganisms, there are only two well-defined clinical and pathological entities, namely Crohn's disease and ulcerative colitis, and we believe that these ileo-caecal lesions should be included in the former category. We do not believe that two different diseases would occur in continuity with each other. It is of significance that in a proportion of the cases of 'regional' or 'segmental' colitis described by Neuman and Dockerty (1954) chronic granulomatous changes with thickening of the bowel wall were prominent features, and the terminal ileum sometimes showed similar changes. Hughes (1963) also described a series of cases of 'right-sided colitis' in which the pathological changes were predominantly those of Crohn's disease. These conditions appear to be similar to cases in our series, and should probably also be classified as Crohn's disease. In the diagnosis of ileo-caecal lesions, undue emphasis may be placed on so-called specific histological changes; the 'crypt abscess', for example, is by no means pathognomonic of ulcerative colitis, being found in relation to simple and malignant colonic tumours, colostomies, and amoebic dysentery (McAllister, 1962). Diagnosis should be based on consideration of the overall clinical and pathological picture.

None of our cases corresponds with the enterocolitis described by Cooke and Brooke (1955), a disease also affecting the right side of the colon but accompanied by small bowel dysfunction and commonly by parenchymal liver damage (Brooke, 1959). Pathologically this disease is ill defined, although it appears to resemble Crohn's disease but without great thickening of the bowel wall. We feel that neither the presence of steatorrhoea nor liver damage constitute evidence for the specificity of an intestinal disease. The concept of entero-colitis as a distinct disease entity, although perhaps useful clinically, is thus accepted with reluctance.

With regard to therapy, most of our cases were treated by local resection and the results seem to be satisfactory. The recurrence rate is much as would be expected in Crohn's disease. Of the 11 cases which we have diagnosed as Crohn's disease, five remain well five or more years after their last resection. Only two patients are known to have had recurrences, and both have fewer symptoms than before the initial treatment. The two surviving patients with ileocaecal tuberculosis remain as well as would be expected.

We would therefore advocate local resection as the treatment of choice in granulomatous disease of the ileo-caecal region, accepting the risk of recurrence and avoiding the sacrifice of too much bowel tissue in the early stages of the disease.

Our thanks are due to Mr. G. Donald for the preparation of the table and diagram and to Mr. G. Kerr for the photomicrographs, and to the surgical staff of the Western Infirmary for permission to study their patients.

\section{REFERENCES}

Brooke, B. N. (1959). Granulomatous diseases of the intestine. Lancet, 2, 745-749.

Butler, E. C. (1956). Right-sided colitis. Gastroenterologia (Basel), 86 , 615-618.

Cooke, W. T., and Brooke, B. N. (1955). Non-specific entero-colitis. Quart.J. Med., 24, 1-22. 
Hughes, E. S. R. (1963). Right-sided colitis. Gut, 4, 316-321.

Lumb, G. (1951). Cicatrizing enterocolitis. Brit. J. Surg., 39, 233-243.

McAllister, T. A. (1962). Diagnosis of amoebic colitis on routine biopsies from rectum and sigmoid colon. Brit. med. J., 1, 362-364.

Lockhart-Mummery, H. E., and Morson, B. C. (1960). Crohn's disease (regional enteritis) of the large intestine and its distinction from ulcerative colitis. Gut, 1, 87-105.
Neuman, H. W., Bargen, J. A., and Judd, E. S. Jr. (1954). A clinical study of 201 cases of regional (segmental) colitis. Surg. Gynec. Obstet, 99, 563-571.

- and Dockerty, M. B. (1954). The pathology of regional (segmental) colitis. Ibid., 99, 572-579.

Watson, A. J., and Roy, A. D. (1960). Paneth cells in the large intestine in ulcerative colitis. J. Path. Bact., 80, 309-316.

Yarnis, H., Marshak, R. H., and Crohn, B. B. (1957). Ileocolitis. J. Amer. med. Ass., 164, 7-13. 